\title{
Structures Controlling Hydrocarbon Migration and Retention: Effective Seismic DHI
}

Rogério de Araújo Santos ${ }^{1}$, José Ricardo B. da Silva², Carlos Bessa Ferreira², Marcelo V. da Silva Alvarenga², Ruan Costa Borges $^{2}$, Eliane da Costa Alves ${ }^{1}$, 1 - UFF (Universidade Federal Fluminense), 2 - Schlumberger.

Copyright 2021, SBGf - Sociedade Brasileira de Geofísica

This paper was prepared for presentation during the $17^{\text {th }}$ International Congress of the Brazilian Geophysical Society held in Rio de Janeiro, Brazil, 16-19 August 2021. Contents of this paper were reviewed by the Technical Committee of the $17^{\text {th }}$ International Congress of the Brazilian Geophysical Society and do not necessarily represent any position of the SBGf, its officers or members. Electronic reproduction or represent any positon of the Brazilian Geophysical Society is prohibited.

\section{Abstract}

Seismic structures correlated with tectonic structures such as faults and fractures, are currently very well described from 3D data, through many algorithms that use equations that statistically measure the spatial behavior of samples, such as variance, coherence, chaos, semblance, curvatures and others. One of the main roles of these structures in an petroleum system is to control and induce secondary migration of fluids, especially those located in juxtaposition with hydrocarbon carrier zones, acting as major responsible for the immense amount of fluid supply in reservoirs worldwide. One of the difficulties in defining the role of tectonic structures as players in the secondary migration is the seismic resolution and definition of the style of acoustic impedance of these structures that lead to conceptual and empirical knowledge, whether or not they would be conductors of fluids. For such a definition, it is important, besides the geometric establishment of the existence of tectonic structures, to build some seismic direct hydrocarbon indicator. Santos et al (2021), propose a form of semi-automatic mapping, defined as surgical mapping, in which the complete path of secondary fluid migration is detected. This would occur from the first, or deeper, seismic manifestation of a source kitchen, or a hot spot relative to the geological beginning of secondary migration, in which it serves as a sampling seed. In other words, its seismic properties are correlated and possibly connected throughout the seismic volume, up to the point of reaching a specific reservoir and filling it. Here in this work, it is presented and illustrated how it is possible to correlate the presence of faults and fractures to its fluid content, from the perception of the conceptual role of migration and fluid feeding in an oil system, supported, or not, by calibration with wells. and proposed to get benefits of cloud computing taking advantage of cloud elasticity and scalability, with infrastructure on cloud sparing need of high-end hardware to be able to run computing demanding applications.

Examples are presented in the Teapot Dome Field, Wyoming, USA oil field and a proposal is made to get performance benefits from cloud computing by taking advantage of the its elasticity and scalability. This solution requires a cloud infrastructure with cutting-edge hardware to run computing applications.

\section{Introduction}

When it is desired to seismically analyze the role of tectonic structures, faults and fractures, in relation to their hydrocarbon migration capacities, up to the point of feeding a given reservoir, a combination of mathematical, geophysical and geological diagnostics of neighbor seismic samples properties is necessary. Seismic samples are spatially correlated to a certain conceptual knowledge of interpretation for each set of elements of the analyzed petroleum system.

Consequently and in general, for analysis related to 3D seismic structures such as faults and fractures, are adopted attributes using equations associated with statistical measurements for spatial behavior of data samples, such as variance, chaos, semblance, curvature, energy and many others. Marfurt (2018) is an important reference for attributes related to seismic responses from tectonic structures imaged by 3D seismic data. Schneider et al (2016) carry out important studies and build Discrete Fracture Network (DFN) from seismic attributes of coherence. Ghahfarokhi and Wilson (2015) use seismic attributes of samples similarity to extract discontinuities in intensely fractured or flexural zones in the Tensleep reservoirs in the Teapot Dome.

The association of seismic responses to Geological and Petrophysical properties, both correlated to petroleum system elements as factors controlling secondary fluid migration, can be initially understood from juxtaposition of faults and fractures in relation to hydrocarbon carrier zones, which can act as responsible for feeding fluids into reservoirs.

Fluid migration is of great complexity to obtain consistent responses when individualized by seismic attributes. Several authors suggest hybrid attributes or meta attributes (Rooij and Tingdahl, 2017). Mandal and Srivastava (2017) show a good summary and citations for the use of multi-attributes, hybrids and techniques of analysis with artificial neural networks (ANN). However, some conceptual complexity emerges when using hybrid attributes or even unsupervised neural networks: the choice of an attribute that is robust to support good fluid transmissibility responses.

\section{Generic Methods}

Major difficulties to define the role of tectonic structures as actors in the secondary migration of fluids from seismic data arise from the resolution of the style of acoustic impedance for such structures. The style is a factor that should lead to conceptual and empirical knowledge of 
their qualities, in order to be reliable in indicating fluidconducting routes. For such a definition, we should consider a spatial geometric indication about the existence of tectonic structures and their correlation with some direct hydrocarbon indicator.

All seismic indicators of fluid transmissibility along fault and fracture structures are important for a given economic analysis of an oil system. From them, some issues should be solved for a given oil exploration prospect: which migration routes are effective for the risk analysis or which production areas for a given reservoir have been effectively filled with a given fluid. Summarizing, where are the spatial filling locations and where happened the retention.

Santos et al (2021), propose a semi-automatic mapping, defined as surgical mapping, in which the complete path of secondary fluid migration can be detected. This would occur from the first seismic manifestation of a generating kitchen, or from a seismic hot spot relative to a route of an initial secondary migration. It can be considered as a sampling seed, with its seismic properties correlated throughout the entire seismic volume, up to the point of geographically reach a specific reservoir, or multiple reservoirs.

Here in this work, it is presented and illustrated how it is seismically possible to correlate presence of faults and fractures to its fluidic content, from the perception of proximity of some source kitchen, considering the role of migration to charge fluids in a reservoir, either supported or not by well-calibrations. In order to get success in defining the efficiency of faults and fractures in carrying fluids to fill reservoirs from seismic, it is recommended a blend of some geological parameters with their geophysical features. All parameterization and handling of this derived information, relating seismic data to geology, is time consuming and can be optimized by cloud computing solutions.

\section{Seismic Impedance indicating Retention Impedance}

When working with seismic data for petroleum, one of the most important question is whether it can infer, or give indications, about the existence of hydrocarbon accumulations. In this sense, several studies have been conducted using multi-attributes and artificial intelligence in the searching for correlation of post-stacking seismic data with responses associated with petrophysical variations that correspond to the fluid factor in the porous space of a rock.

Searching fluid evidences in post-stacking data has been gaining new scenarios after the great development of seismic methods of $3 \mathrm{D}$ visualization and multi-attributes used to define fluid paths and retention.

Demaison and Huizinga (1991), classify fluid retention in a petroleum system according to their impedance styles, when these would be the migration end-points, which would be strongly depend on the sealing capacity. This classification of trap styles is here expanded to all elements of an oil system, using seismic impedances to indicate the control of each element, since sourcing, suggesting secondary migration paths, the existence of the trap, the capacity of the seal and, more especially, the filling of reservoirs by hydrocarbons. This complete set of petroleum system elements leads to the concept of retention defined by seismic impedance. It is shown that these classifications can be supported by the seismic impedance responses observed in each element, depending on the indicators of pore fluid content, their permeability, and their consequent pressure variations caused by the presence of fluids, impacting on the elastic constant investigated by seismic waves.

Batzle and Wang (1992) show that primary seismic properties of pore fluids (density, bulk modulus, velocity, and viscosity) vary substantially, and systematically, under the pressure and temperature conditions typical of petroleum exploration. They mention that brines and hydrocarbon gases and oils are the most abundant pore fluids and their seismic properties are usually oversimplified in geophysics. They exemplify that light oils can absorb large quantities of gas at elevated pressures significantly reducing their modulus and density.

Ligtenberg (2005) shows the possibilities of detecting fluid migration from post-stacking seismic data, highlighting areas of hydrocarbon expulsion, evaluating the quality of fault seals, with information of charge, escape and leakage of fluid reservoirs

Kluesner and Brothers (2016) present a poststack data conditioning and neural-network attribute workflow for the detection of faults and potential fluid-pathways in a highresolution 3D P-Cable seismic volume. They combine maximum curvature attribute and structural interpretations with the neural-network attribute results, revealing a strong relationship between deformation associated with strike-slip fault kinematics and the distribution of probable fluid pathways.

Whatever the cube for direct hydrocarbon indicators (DHI), we propose it should be effective for all petroleum system elements, where a part of the seismic response is given by the fluid factor and other part given by the rock stiffness factor, as described by Bortfeld (1961) adapting the Zoeppritz equations, simplifying them for the P-wave reflectivity equation of a saturated rock, in response to the incident $P$ wave:

P-wave Reflectivity = Fluid Factor + Stiffness Factor

While genetic classification of Demaison and Huizinga (1991) had the objective of describing and predicting the hydrocarbon load of a petroleum system and, consequently, identifying basin segments to geographically locate areas of occurrence of petroleum or plays, an effective $\mathrm{DHI}$ cube can magnify such concepts. It become seismic responses reasonable for all elements of each investigated oil system. Thus, the genetic classification of such authors, using parameters related to charge factor (super charged, normally charged, and under charged), migration drainage style (vertical or lateral) and trapping style itself (low and high impedances), can be extended, making possible to seismically and effectively characterize such elements. 


\section{Seismic Effective DHI}

Any DHI seismic cube should bring an effective logic to get all valuable information related to economic demands for the interpretation, looking for precision and accuracy of each information, reducing seismic uncertainties. In this sense, it is important that any DHI cube be effective also for a full spatial understanding of the involved elements of a petroleum system.

An effective DHI cube should suggest seismic evidences for each element of the petroleum system: source, migration, charge, seal, reservoir and retention. With these evidences, it is possible to follow the fluid path, from sourcing to reservoir filling. An optimal DHI cube will be one that can show multiple exploration opportunities. To map such opportunities we present the concept of an Effective DHI cube, which should point out suggestions not only to indicate fluid in reservoirs, but also for every element in a petroleum system, as described below:

Effective Kitchen - related to regions in the spatial vicinity of an oil source, which indicate footpaths from the beginning of secondary migration, where the total length of each recorded seismic trace be enough to reach depths in such regions. In this item, there should be a weighted analysis of the fluid and rigidity factors for the source in equation (1).

Effective secondary migration - with pathways of fluid carrying areas, pervasive, stratigraphic or due to faults and fractures, must be basically diagnosed by the fluid factor of equation (1)

Effective seal - that describes the level of sealing resistance (impedance that works against the dispersion of the petroleum charge). In this case, rock stiffness factor and its physical and hydraulic resistance to trapping and pressure of the underlying fluid would give predominantly the reflectivity in (1)

Effective reservoir - regions classified as having high impedance indicating hydrocarbons, producing significant variations in the fluid factor in equation (1), while having low impedance for dry regions in terms of hydrocarbons, or variations with very small magnitude, mainly associated to rigidity factor in equation (1).

Thus, whichever DHI cube proposed to be effective in detecting or suggesting the presence of accumulations of hydrocarbons, it should be an effective indicator also for all the factors described by equation (1), or by any other solution derived from Zoeppritz equations or even similar ones.

\section{Effective DHI: on example for Tea Pot Dome}

Effective indication for the seismic response from source, secondary migration, seal and reservoir, allied to the fluid content indication, can be directly related to the roles of faults and fractures. To be successful in defining fault and fracture effectivities, in fluid expulsion from source, driving fluids to fill reservoirs, retain fluids into reservoirs, it is necessary to combine countless hypotheses and options of both Geological and Petrophysical parameters with several Geophysical parameters. The required parameterization and proper handling of those innumerous information, can be optimized by using cloud computing.

Nowadays cloud computing has been gaining more popularity and grabbing the attention from the whole industry. Looking at the prism of geoscience applications can take advantage of cloud scalability and elasticity.

Scalability is the ability of infrastructure to accommodate huge workloads adding resources either increasing hardware specification. Meanwhile elasticity is one of the key features in cloud computing that dynamically adjusts the amount of allocated resources to meet changes in workload demands. This study takes advantage of cloud capabilities to run geoscience applications providing all necessary infrastructure on cloud sparing need of highend hardware to be able to run computing demanding applications.

These technologies and techniques are exemplified here: the effectivity of a DHI cube that potentiates the suggestion of the presence of impedances that indicate effective factors described by equation (1) for the field of Teapot Dome, USA, enhancing secondary migration and hydrocarbon retention controls.

\section{Teapot Dome Field: Geological Setting}

Teapot Dome Field is close Salt Creek field, on a structure that is part of the Salt Creek anticline, and has an area of 9481 acres. Stratigraphically, they are Paleozoic sediments that cover the Precambrian basement, consisting of thin intercalations of sandstones, limestones, dolomites, shales and salts. The field production is mostly associated with the Pennsylvanian Tensleep wind sandstone with thicknesses around 300 feet, but dolomites are also important.

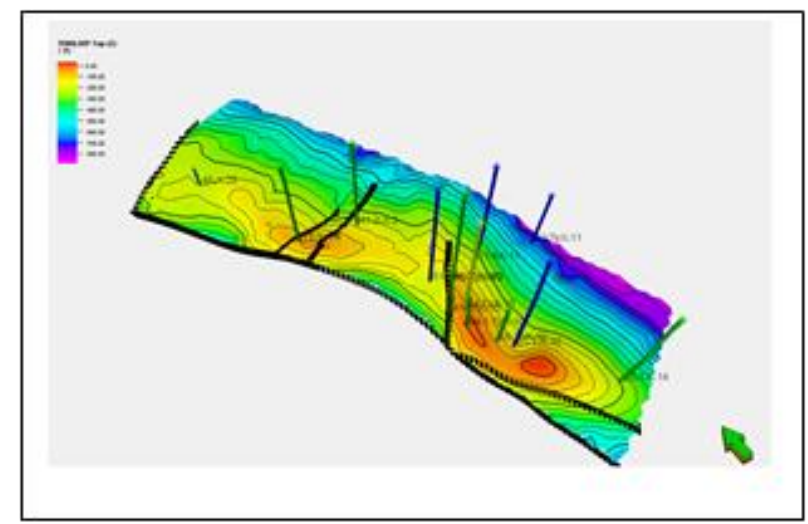

Figure 1 - Seismic surface TWT(ms) correlated to Tensleep formation top.

Momper and Williams (1979) cite that the generation of petroleum would be very distant, in the formation of Phosphoria of the Permian, and that it is not covered by the seismic data here analyzed.

Nummedal et al (2003), record that of the more than 1300 wells drilled, 27 were drilled to evaluate the Tensleep formation, of which only 13 would still be active. The 
authors also mention that where the oil is not trapped, there is an aquifer in a thick porous and permeable sandstone.

Tensleep formation is divided and characterized into different zones based on the depositional characteristics. In the basal part, sand dunes and carbonates form unit $\mathrm{C}$. Immediately above, wind dunes were deposited in unit $\mathrm{C}$. Just above unit $B$, with shallow water carbonates (dolomites) and finally unit A shows wind dunes again.

The Opeche shales, originating from a coastal plain in the Goose formation, would seal trapped hydrocarbon in the Tensleep formation.

Here, we focus on the Tensleep formation in its eolian sandstones $B$, the most productive in the field, with about $60 \%$ of the oil produced, with porosities around $10.8 \%$, vertical permeability of $6.5 \mathrm{mD}$ and horizontal of $20.2 \mathrm{mD}$. We also investigate $\mathrm{C}$ dolomites close to the base of the Tensleep Formation, with a porosity of $15 \%$ and vertical permeability of $0.338 \mathrm{mD}$, observed by Numedal et al (2003) in well 48-X-28.

We analyze how faults and fractures can be detected from 3D seismic data in the study area, combining the trapping and seal styles, as defined by their impedances according to Demaison and Uizinga (1991). Zahm and Hennings (2009) show that fracture prediction methods commonly neglect the inclusion of stratigraphic architecture as part of the forecasting or characterization process.

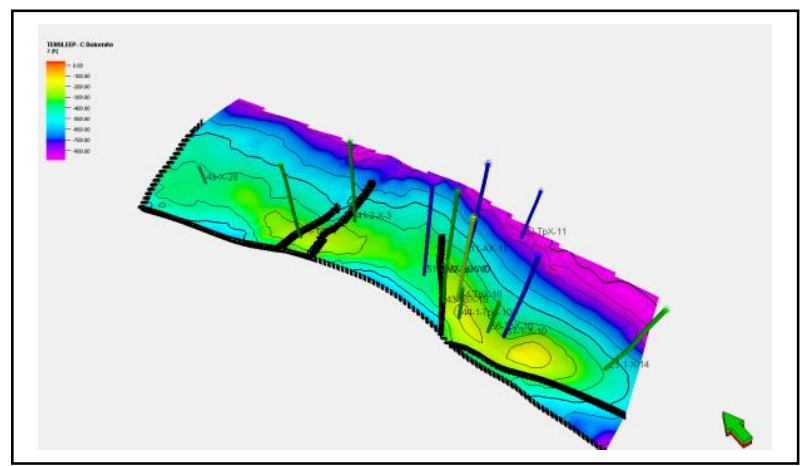

Figure 2 - Seismic surface TWT $(\mathrm{ms})$ related to Dolomite C zone top.

Here we take care about it, once this inclusion can be critical for secondary migration, as the development of complex heterogeneous fractures occurs within the Tensleep eolian sandstone. To understand the relationship between hydrocarbon carrier zones and juxtaposition of faults and fractures, Ghahfarokhi and Wilson (2015) mention that in Teapot Dome exists a qualitative correlation between production data and extracted discontinuities, and suggest that the wells located in the articulated oblique discontinuities are more productive than other wells in the field. Retention in such regions are enhanced, and impedance variation in traps increases.

A basic question about getting success in areas geologically similar to the Teapot Dome is related to two seismic analysis: Definition of low amplitude heterogeneities, which are very affected by apparent attenuation of seismic waves (Santos et al, 2019), and seismic identification of the best regions for retention of hydrocarbons. These two aspects should guide the entire treatment of seismic information for effective DHI cubes generation.

It is important to apprehend that seismic average amplitudes nearby the top of a given reservoir, where there is a top or lateral good seal, can be related to fluid retention.

Figure 3 shows a perception of the average amplitudes close to the top of the Dolomite $C$ reservoir of the Tensleep formation, where the best amplitudes are associated to the $\mathrm{W}$ margin of the block and not controlled by the faults most clearly defined by $3 D$ seismic.

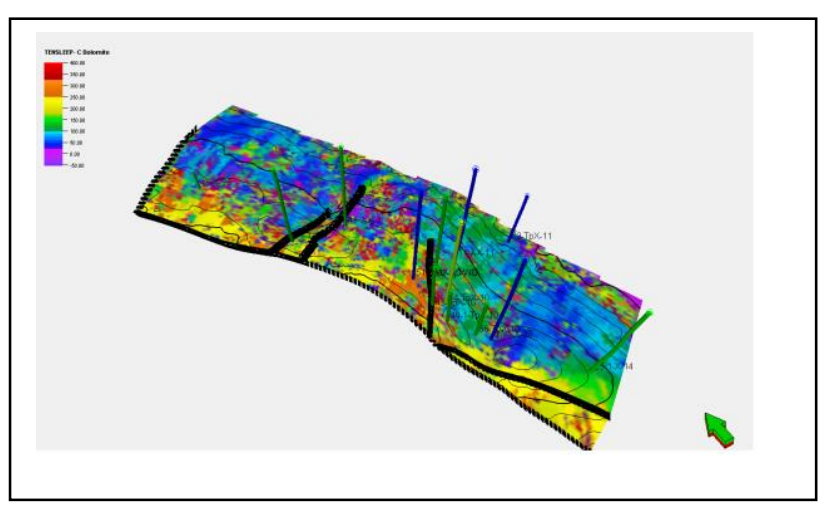

Figure 3 - Dolomite C - Conventional Amplitudes

Figure 4 illustrates in lilac colors the projection of oil retention on top of the Tensleep Formation indicated by an effective $\mathrm{DHI}$ cube derived from PSTM qualification processing as described in Santos et al (2019). It would concentrate on the NW edge of the seismic block made available for this study, with a clear structural discontinuity in the NW-SE direction. It would also concentrate on the SE edge of the block, as shown by well $25-1-\mathrm{X}-14$.

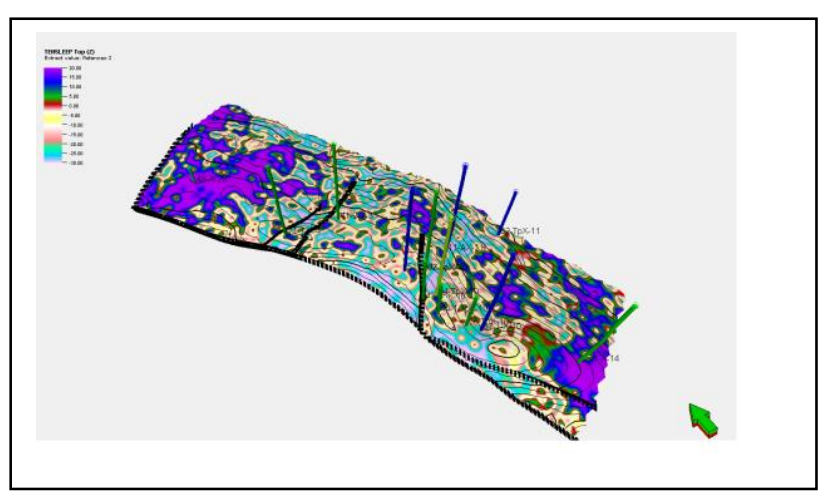

Figure 4 - Effective DHI cube surface suggesting better areas for retention at Tensleep Formation top 
In Teapot Dome, Santos et al (2019) show the importance of structural discontinuities, almost sub-seismic, that can control the migration of fluids and, thus, generate other exploratory opportunities in the area, as shown here.

When comparing with the average values of the adopted $\mathrm{DHI}$ cube magnitudes, better retention regions would be also related to the NW and SE edges of the block, also as sampled by the producer well 25-1-X-14. It happens with structural control by discontinuities in lineaments that are not so easily observed by seismic amplitude heterogeneities, N-S and WWN-EES directions, as illustrated in Figure 5.

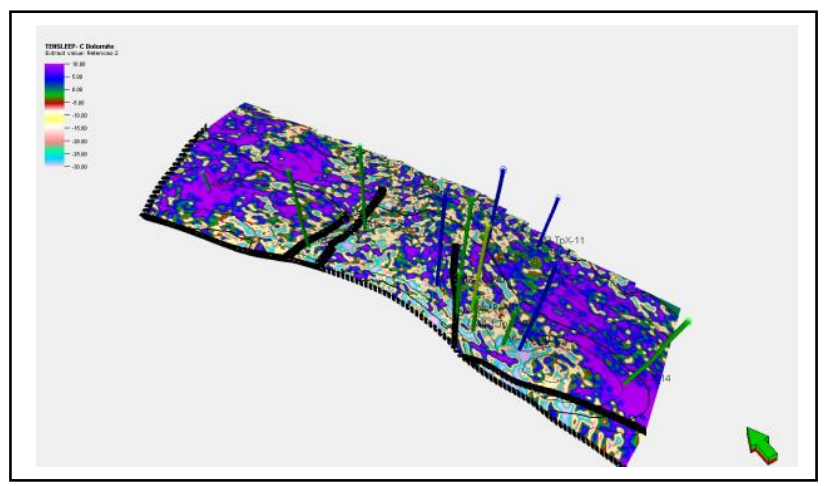

Figure 5 - Effective DHI cube surface suggesting better areas for retention at Dolomite $\mathrm{C}$ top.

A detailed indication for retention time slice is shown in Figure 6, highlights the well 25-1-X-14 in green, oil-well, in the high impedance lilac zone, and the dry wells (in blue). We show contrast impedance indicating retention system, with zones of fracture logs, in red FCNB (cumulative number of fractures in the uphole direction) and FCAP in green (cumulative mean aperture in the uphole Direction).

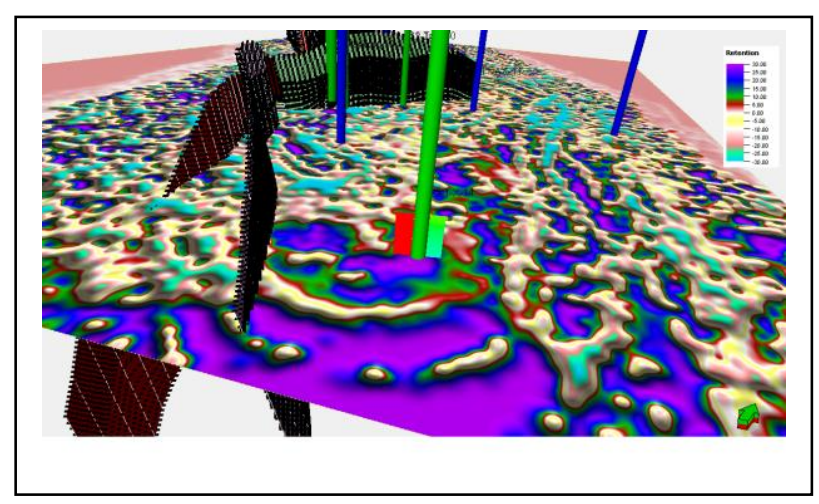

Figure 6 - Effective DHI cube in a detail for the well 25-1$X-14$ in green, oil-well, in the high-impedance retention zone (seal associated with trap). Blue dry wells in the low impedance area of the retention and trap system.
Comparing this result with image in Figure 3 , it is important to observe that the suggested accumulation is not controlled by the fault indicated in amplitude data, with NNW-SSE direction. However, in the $5653 \mathrm{ft}$ slice data, retention indicator suggests that there is a clear control of such values in the direction of NNE-SSW.

\section{Conclusions}

Concepts of effective DHI cube is presented, which suggest, and possibly quantify, regions that not only the confined presence of a certain accumulation, but also indicate the role and relevance of all elements of a petroleum system, suggesting its relations with the sourcing, fluid distribution and retention.

It is shown that the quality of a DHI cube in this sense, can establish new guidelines for exploration and production of hydrocarbons. In Teapot Dome field, a more detailed exploration of the NW and SE edges of the seismic block is here suggested.

\section{Acknowledgments}

We would like to thank Schlumberger for the granting of Petrel's academic licenses and the available data to Universidade Federal Fluminense - UFF and to UFF by the possibility of this research.

\section{References}

BATZLE, M. and WANG,Z.J.. 1992. Seismic properties of pore fluids 1992 Society of Exploration Geophysicists. All rights reserved. GEOPHYSICS, VOL. 57, NO. 11 (NOVEMBER 1992); P. 13961408, 17 FIGS., 1TABLE.

BORTFELD, R., 1961. Approximations to the reflection and transmission coefficients of plane longitudinal and transverse waves. First published: December 1961 https://doi.org/10.1111/j.1365-78.1961.tb01670.x

Citations: 147 Presented at the Nineteenth Meeting of the European Association of Exploration Geophysicists, held in Paris, 7-9 December 1960.

DEMAISON G. and HUIZINGA B.J.,1991. Genetic Classification of Petroleum Systems. AAPG Bulletin 1991; 75 (10): 1626-1643.

GHAHFAROKHI, P. K. and WILSON, T.H., 2015. Fracture intensity attribute for the Tensleep reservoir at Teapot Dome, Wyoming, Interpretation, Vol. 3, No. 3 (August 2015); p. SZ41-SZ48, 9 FIGS.

KLUESNER,J.W.; and BROTHERS,D.S., 2016. Seismic attribute detection of faults and fluid pathways within an active strike-slip shear zone: New insights from highresolution 3D P-Cable ${ }^{\mathrm{TM}}$ seismic data along the Hosgri Fault, offshore California. Interpretation 4(1):SB131SB148. DOI:10.1190/INT-2015-0143.1. 
LIGTENBERG, J.H., 2005. Detection of fluid migration pathways in seismic data: implications for fault seal analysis dGB Earth Sciences, Enschede,The Netherlands Basin Research (2005) 17, 141-153, DOI: 10.1111/j.1365-2117.2005.00258.x.

MARFURT,K. J., 2018. Seismic Attributes as the Framework for data Integration throughout the oil field life cycle http://repository.uwyo.edu/petro_senior_design/3 Copyright year: 2018 Pages: 508 Publisher: Society of Exploration Geophysicists.

MOMPER, J. A. and WILLIAMS, J. A., 1984, Geochemical exploration in the Powder River basin,in G. Demaison, and R. J. Murris, eds., Petroleumgeochemistry and basin evaluation: American Association of Petroleum $\begin{array}{llll}\text { Geologists } & \text { Memoirs } & \text { 35, } & 181-191\end{array}$

NUMMEDALI, D.; TOWLER, B.; MASON, C.; ALLEN, M., 2003. Enhanced Oil Recovery in Wyoming: Prospects and challenges . Laramie, Wy: University of Wyoming.

SANTOS, R.; SILVA, J.R., ALVES, E.; ALVARENGA, M. 2019. Seismic Data Qualifying for Fracture Detection Along E\&P Interpretation Processes: 16th International Congress of the Brazilian Geophysical Society. Rio de Janeiro, Brazil, 19-22.

SANTOS, R.A.; ALVES. E.C.; RAMOS. E., 2021. Follow the Fluid: The importance of Surgical Interpretation in a $\mathrm{DHI}$ seismic volume. Submitted to 17th International Congress of the Brazilian Geophysical Society held in Rio de Janeiro, Brazil.

SCHNEIDER, S.; EICHKITZ, C.G.; SCHREILECHNER, M.G.; DAVIS, J.C.,2016 Interpretation of Fractured zones using seismic attributes - Case Study from Teapot Dome, Wyoming, USA. Interpretation, Vol. 4, No 2: $p$ T249-T260, 11 Figs.

SRIVASTAVA, E. and MANDAL, A., 2017. Seismic data conditioning and multiattribute analysis for enhanced structural interpretation: A case study from offshore Nova Scotia, Scotian Basin

https://doi.org/10.1190/segam2017-17778902.1

TINGDAHL. K. M. and M. DE ROOIJ, 2005, Semiautomatic detection of faults in 3D seismic data: Geophysical Prospecting, 53, 533-542, http://dx.doi.org/10.1111/j.1365-2478.2005.00489.x.

ZAHM, C.K. and HENNINGS, P.H., 2009. 3D seismic curvature and flexure for unconventional fractured reservoir characterization at Teapot Dome (Wyoming), AAPG Bulletin 93 (11): 1427-1446 